\title{
PAIXÕES E RIVALIDADES FUTEBOLÍSTICAS EM UM DESFILE DE ESCOLA DE SAMBA DO RIO DE JANEIRO
}

Estélio Gomberg

O objetivo do artigo é apreender os contextos de inversões das paixões futebolísticas que se manifestaram no desfile da Escola de Samba Unidos de Vila Isabel, no Rio de Janeiro, em 1996, no qual sentimentos de pertencimento futebolístico foram deslocados para a esfera de sociabilidade. [abstract on page 281]

CARNAVAL, UNIDOS DE VILA ISABEL, FUTEBOL. 


\section{APRESENTAÇÃO}

1 As referências consultadas sobre a história dessa escola de samba (ARAGÃO, 1997; CABRAL, 1996; RIOTUR, 1992; DA VILA, 1992; GUILLERMOPRIETO, 1991; REGO, 1987; e JÓRIO E ARAÚJO, 1969) atestam, consensualmente, que o marco de sua organização foi à admiração de Antônio Fernandes Silveira (seu China) pela apresentação de um bloco carnavalesco na principal avenida do bairro de Vila Isabel, Boulevard 28 de setembro, em 1946.
Em 1996, a Escola de Samba Unidos de Vila Isabel ${ }^{1}$ apresentou no desfile do grupo especial do Rio de Janeiro o enredo "A heróica cavalgada de um povo", inspirado na história do Rio Grande do Sul, região meridional do Brasil.

Ocupando posição muito particular em relação ao restante do Brasil, esse estado possui representações relacionadas, de forma geral, ao passado rural, aos primeiros tempos de ocupação do território e da constituição das grandes propriedades dedicadas à criação de gado - as estâncias (OLIVEN, 1992; PESAVENTO, 1982).

Os diversos conflitos registrados nessa região contribuíram de forma significativa para a imagem do gaúcho enquanto guerreiro, bravo, heróico e valente, adjetivos que lhe são atribuídos, atestando-lhe qualidades que acabam por tornar-se algumas de suas mais fortes marcas identificatórias (MACIEL, 1994).

Também a composição da população rio-grandense para a qual concorreram diversas etnias, especialmente, alemães e

italianos, é considerada particular, tendo o estado uma imagem de diversificação étnica. Esses imigrantes contribuíram igualmente no sentido de conferir ao rio-grandense a imagem de povo produtivo e trabalhador e ao Rio Grande do Sul a de Celeiro do Brasil.

Durante a preparação do desfile, podemos perceber certo questionamento que pairava, na visão dos componentes da Escola de Samba Unidos de Vila Isabel, sobre a falta de combinação entre a cultura gaúcha e a cultura do Brasil, no caso, em especial, a festa nacional - o carnaval.

\section{GAÚCHO DÁ SAMBA?}

Essa interrogação feita por um integrante da escola de samba focalizada traduz a visão comum da relação de distanciamento que pauta as relações geográficas, sociais e culturais, nos diversos planos, entre os gaúchos e os outros (do Brasil) e/ou os outros (do Brasil) e os gaúchos.

Considerar o Brasil "país do carnaval" propicia leitura única e sintética da complexidade e das distinções das manifestações carnavalescas que são apresentadas nas diversas regiões do país (GOMBERG, 1998). Por sua vez, a colocação singular e totalizante traz para essa festividade o sentido de símbolo nacional que foi sendo concebido ao longo dos períodos históricos (DAMATTA, 1979, QUEIROZ, 1992).

O desfile em questão buscou, assim, no plano da encenação e através de diversas linguagens, aglutinar esse caleidoscópio sociocultural que marca a sociedade brasileira em momentos do cotidiano e extraordinários. 


\section{A PREPARAÇÃO DE UM DESFILE DE ESCOLA DE SAMBA}

O enredo de uma escola de samba, estruturado por um samba-enredo, alegorias e fantasias, possibilita traduzir temas, imagens e sentimentos que operam no conjunto de representações visando ao entendimento daquilo que almeja ser apresentado no desfile.

Esse enredo em particular foi construído, desenvolvido e apresentado por essa escola de samba procurando verificar as imagens e representações relacionadas ao Rio Grande do Sul e seu habitante - o gaúcho.

Partindo dessas representações, procuramos na apresentação das fantasias de times de futebol do estado homenageado apreender como foram concebidas e transformadas no sentido de constituir um espetáculo, ou simplesmente carnavalizadas, e o grande valor afetivo desse gesto para o desfilante.

O termo carnaval, argumenta Bakhtin, reúne várias festividades populares que acontecem em diferentes datas e espaços, mas que são possuidoras de características comuns: "O denominador comum de todas as características carnavalescas que compreendem as diferentes festas é a sua relação essencial com o tempo alegre. Por toda parte onde o aspecto livre e popular se conservou, essa relação com o tempo e, consequentemente, certos elementos de caráter carnavalesco, sobreviveram" (BAKHTIN, 1987, p. 191).

As festividades, qualquer que seja sua natureza (religiosa ou não religiosa) são: uma forma primordial, marcante da civilização humana. Não é preciso considerá-las nem explicá-las como um produto das condições e finalidades práticas do trabalho coletivo nem, interpretação mais vulgar ainda, da necessidade biológica (fisiológica) de descanso periódico. E acrescenta que elas tiveram sempre um conteúdo essencial, um sentido profundo, exprimiram sempre uma concepção de mundo (BAKHTIN, 1987, p. 7).

Ainda segundo esse autor, no final da Idade Média e na Renascença, o carnaval representava um papel simbólico na vida das pessoas, ou seja, colocava-se na esfera da liberdade utópica e expressava cosmovisão alternativa às normas sociais.

Da mesma forma, Baroja (1989), analisando o termo carnaval na península ibérica, aponta que ele é caracterizado por um tempo em que o homem relega o trabalho a segundo plano, sendo as diversões e a liberdade seus elementos fundantes.

O sentido da liberdade, na opinião de Bakhtin, era vivido intensamente e constituía a essência da visão carnavalesca do mundo. As distâncias entre os indivíduos ficavam abolidas, e eram estabelecidas outras regras de conduta e nova linguagem. A atitude carnavalesca era imperativa.

Outro aspecto que permaneceu nas festividades do carnaval são as formas de vestir, especialmente no que concerne a fantasias e máscaras. Esses disfarces possibilitam representar personagens, romper com a ordem estabelecida e provocar situações cômicas. 
No processo de carnavalização, os heróis e os mitos são intencionalmente exagerados e modernizados. Por isso, essa percepção carnavalesca possui um poder extraordinário de transfigurar e carnavalizar a visão do mundo. Por carnavalização, Bakhtin (1981, p. 151) designa um processo da mistura de "gêneros diferentes, exteriormente variados, mas ligados por um parentesco interno que constituíram um domínio especial da literatura, que os antigos denominam figurado, isto é, que misturava o prazeroso ao sério".

O carnaval, observa o autor, não é somente uma prática social específica, mas também uma espécie de "reserva" geral e perene de formas populares e rituais festivos. Nesse sentido, o carnaval de Bakhtin se assemelha às categorias de "communitas" e "rituais liminares" de Turner (1974, p. 5):

um relacionamento não estruturado que muitas vezes se desenvolve entre liminares. É um relacionamento entre indivíduos concretos, históricos, idiossincráticos. Estes indivíduos não estão segmentados em funções e status mas encaram-se como seres humanos totais.

No carnaval brasileiro, o cômico se expressa na manifestações de rua por intermédio de foliões, blocos e fantasiados criticando a ordem vigente. Por sua vez, nos desfiles das escolas de samba registra-se a ausência desse elemento, pois se caracterizam por outras formas de expressão além do cômico - uma estética popular que aspira à beleza, ao luxo e ao brilho. Nessa visão de mundo, o espaço é impregnado pelo fantástico e pela imaginação.

Desse modo, o imaginário social torna-se importante para a elaboração e concretização do presente objeto de pesquisa porque é elemento eficaz na organização de uma coletividade através do exercício do poder e da autoridade, sendo ainda uma resposta a eventuais crises, conflitos ou divisões.

É através de seus imaginários sociais que uma coletividade elabora sua representação, podendo esta não ter relação direta com a realidade, uma vez que é revestida de intenção, manipulação e ilusão.

As suas junções e disjunções efectuam-se segundo diversas modalidades, diferenciadas consoante as características específicas de um dado campo social e mental (estruturas sociais, sistemas de poder, intensidade de conflitos sociais, sistemas de valores dominantes e concorrentes, simbolismo e ritual instalado, meios e técnicas de difusão das informações e símbolos, etc.) (BACZKO, 1985, p. 312).

Essa complexa rede atua na transformação de desejos, sentimentos, esperanças, redes simbólicas:

os imaginários sociais fornecem, deste modo, um sistema de orientações expressivas e afetivas, que correspondem a outros tantos estereótipos oferecidos aos agentes sociais: ao indivíduo relativamente aos grupos sociais relativamente à sociedade global, às suas hierarquias e relações de dominação, etc. (BAZCKO, 1985, p. 311). 
Produz-se assim uma representação global e totalizante da sociedade como uma ordem, a partir da qual cada elemento busca encontrar seu lugar, sua identidade e sua existência.

Domínio das variedades dos níveis de imagens (tais como as impressas, as imagens poéticas e as imagens iconográficas), o imaginário formula o real e pelo real é trabaIhado, num constante movimento de circularidade.

O imaginário permeia a trama representativa do carnaval através da dramatização plástica colocando em foco as diferenças, as tensões, as satisfações, as fantasias e as alegorias que agem no vivenciar mágico de necessidades e de desejos e nas vivências representativas e imaginárias.

O carnaval brasileiro é percebido por Roberto DaMatta (1979) como um ritual que contém múltiplos planos, reúne elementos díspares da sociedade e, através da dramatização, revela valores da sociedade brasileira.

O autor aponta o significado da inversão do carnaval do Rio de Janeiro, projetando para o nacional, relacionado ao cotidiano da sociedade brasileira, revelando modificações no comportamento. A inversão, através do deslocamento de elementos díspares no cotidiano, possibilita a junção desses elementos.

Sua análise parte da comparação do carnaval com outros rituais, como as paradas civis e procissões religiosas, em que visa tecer a identidade do "ser brasileiro". O carnaval, em sua visão, aparece como um "rito de inversão" e, em sua análise, deve-se considerá-lo ritual nacional e "informal" organizado através de associações "inclusivas", apresentando caráter de agrupamento aberto.

Devemos considerar que o carnaval brasileiro é muito mais variado do que a análise de DaMatta, dada a multiplicidade de manifestações nas diversas regiões do país tanto em termos de classe quanto de grupos étnicos ou períodos históricos. Enquanto a retórica do carnaval tende a inverter as hierarquias da vida social cotidiana, a prática do carnaval às vezes também dramatiza essas hierarquias.

Por sua vez, Maria Isaura Pereira de Queiroz (1992) mostra a transformação do carnaval em símbolo nacional e em que momento da sociedade brasileira isso ocorreu. Traça uma cronologia do carnaval em fases, correspondentes à prevalência da forma de brincar. Contudo, devemos fazer análise mais apurada do que a periodização sugerida por Pereira de Queiroz para evitar noção totalizante de compreensão da festa.

O estudo de Maria Laura Cavalcanti (1994), realizado na Escola de Samba Mocidade Independente de Padre Miguel, enfatiza o papel das redes de relações articuladas à sociedade global, de atores sociais que produzem o desfile e da relação com o jogo do bicho. Nessa produção, o carnavalesco ocupa papel central como mediador. A autora destaca essa atividade como portadora de nítida ambiguidade na relação trabalho/lazer, em que o trabalho se mescla a situações de brincadeiras e de jocosidades: “Uma das alegrias do carnaval e uma de suas muitas subversões é certamente a dissolução trabalho e la- 
zer, ou trabalho e festa. Trabalhava-se em festas e fazendo festas" (CAVALCANTI, 1994, p. 189).

Os estudos de DaMatta $(1977,1979)$ são referência para pensar o carnaval brasileiro através da teoria do ritual, pois buscam, através de sua comparação com outros rituais nacionais, a apreensão de uma identidade nacional.

É importante salientar que estamos tratando de escola de samba, que é tida como "de raiz" (de tradição) e em que se evidencia forte sentimento de pertencimento à agremiação e se manifesta tensão estruturante entre "samba no pé"² e "primazia do visual".

2 Expressão popular que designa a imagem corporal que marca o bom sambista.

3 Sobre o compositor Noel Rosa, ver Máximo e Didier, 1990; Ribeiro, 1995 e Tota, 2001.
O "samba no pé" remete às origens da agremiação e a sua identidade, ligada ao bairro carioca de Vila Isabel, de características culturais boêmias, em virtude de lá ter nascido um dos maiores sambistas urbanos brasileiros, Noel Rosa. ${ }^{3}$ Por sua vez, a "primazia do visual" coloca a dimensão plástica do desfile, aponta para o processo de modernização e acentua o caráter de espetáculo. Essa é tensão que perpassa os vários desfiles em função das transformações ocorridas ao longo do tempo.

As escolas de samba são consideradas agremiações culturais e recreativas para fins carnavalescos e estruturadas na ordem e no planejamento de sua apresentação. Maria Julia Goldwasser (1975) indica a existência de um "saber carnavalesco" para caracterizar a coordenação do tema de enredo com ritmo, movimentos, materiais e tonalidades para formar o conjunto no desfile.

As alas são as unidades mínimas de uma escola de samba, tendo o presidente ou o diretor atribuições de escolha, de confecção e de comercialização de suas fantasias. "Toda a estrutura do desfile é modelada sobre o cálculo das alas, desde a distribuição de papéis dramáticos e esquematização de figurinos ao rateio de subvenções para as fantasias" (Goldwasser, 1975, p. 71).

As fantasias das alas e dos destaques são importantes elementos comunicativos do enredo na apresentação de uma escola de samba, posto que auxiliam o entendimento do enredo. A confecção das fantasias ocorre nos "ateliês", que se organizam, em sua maioria, através das relações familiares e de vizinhança; com a crescente importância da produção do desfile, porém, muitas alas têm suas fantasias confeccionadas em ateliês profissionais contratados sem ligação direta com a escola.

A ala possibilita a abertura da escola de samba para a sociedade mais ampla, permitindo a participação daqueles que não são da comunidade da escola. Assim, diversos segmentos sociais, internos e externos à agremiação, podem congregar-se no interior da ala desde que usem a fantasia correspondente.

A fim de preencher as alas com um número satisfatório de desfilantes nesse ano, a Unidos de Vila Isabel, além de seus "componentes", contactou uma empresa de turismo de Porto Alegre para comercializar fantasias e possibilitar a participação de gaúchos 
- participação de caráter efêmero, diga-se de passagem, pois ocorreu apenas nesse desfile em particular, sem estabelecer laços maiores e permanentes com a escola de maneira geral.

O interessado em adquirir uma fantasia observava na empresa o "book da Escola", com informações sobre enredo, orçamento, figurinos das fantasias além das especificações das plantas baixas dos carros alegóricos. Segundo relatos, a escolha era feita principalmente em função do interesse em estar junto com outros gaúchos, desfilando na mesma ala, e só posteriormente vinculava-se a fatores estéticos da fantasia, demonstrando a primazia do fator de sociabilidade sobre o do visual, contexto tão próprio do desfile de escola de samba.

A grande disputa era: sou gremista e ele é colorado. Cada um doente do seu lado. A grande disputa era ver qual a fantasia que a gente queria desfilar. No final, fizemos uma opção por custo. O que nos interessa é a farra. Então, vamos na fantasia que é mais barata. Acabamos fazendo esta opção pela fantasia do Inter (Carlos, gaúcho, ala do Internacional).

Torço pelo Grêmio. Foi mais pelo carnaval. Acho que ali, naquela hora não era tanto pelo Grêmio, pelo colorado. Era mais estar desfilando por uma escola. A gente até esquece um pouco o que está vestindo. É mais aquele envolvimento todo de carnaval (Élton, gaúcho, ala do Internacional).

A essência do lúdico, intrínseco no carnaval das escolas de samba do Rio de Janeiro, manifesta-se como espetáculo complexo, ora agregando diversos sujeitos sociais, ora separando através dos diversos setores de apresentação e de público. Seus participantes não atentam no fato de que a relativa democracia, "comunhão", que existe na festa é tradução realista dos interesses primordiais do desfile, focados especialmente no âmbito da competição, e, diante disso, a própria espetacularização é ratificada no uso da fantasia, um dos elementos do enredo, agregando expressão dos sinais e dos signos a serem entendidos pelos assistentes, presentes na Passarela do Samba ou a ela conectados pelos diversos meios de comunicação.

Os integrantes desejavam brincar vestidos com fantasias remetendo aos times de futebol, paixões de suas vidas cotidianas, apontando uma transformação lúdica em busca de representações do imaginário coletivo, trocando interesses e pertencimentos futebolísticos. Isso se revelou nas escolhas de fantasias de times de futebol rivais em um momento transitório - o do desfile. Os contextos concebidos parecem funcionar para atender a uma finalidade particular, sendo apenas fruto da imaginação, mas atentamos para o que consideramos ser almejado, acima desse sentimento: estar socialmente agregado nesse evento, articulando padrões, comportamentos e signos para atingir mecanismos de comunicação como membro participante do desfile.

\section{COLORADOS DE GREMISTAS E GREMISTAS DE COLORADOS}

Antes do desfile, em frente às barracas de comidas e bebidas na Área de Concentração, encontravam-se pequenos grupos de integrantes da Unidos de Vila Isabel - alguns sem se conhecerem - portando suas fantasias e aguardando o momento de entra- 
da na Área de Armação. Ali se mesclavam desfilantes, pessoas conhecidas e curiosos que apreciavam a movimentação, as fantasias e a armação da escola de samba, criando desse jeito relações de confraternização e solidariedade.

Tal situação também é apresentada por DaMatta $(1985,1994)$ em sua reflexão acerca do futebol, terreno em que ocorre igualdade de disputas entre os participantes na sociedade hierárquica e em que as camisas dos times acabam por promover aproximação de torcedores mesmo de distintas posições sociais.

Assim, fantasias e camisas de times de futebol operam com significados equivalentes, ou seja, identificam pertencimento e estabelecem laços de interações entre diversos sujeitos sociais.

De fato, é o momento da interação e da confraternização. É o momento em que os participantes se tornam uma escola, em que a solidariedade grupal tece e estabelece seus laços unindo o coletivo. Mesmo assim, elementos de insatisfação podem surgir, como a devida à confecção de baixa qualidade de algumas fantasias por exemplo, a de saci-pererê.

Essa insatisfação estava relacionada à diferença de produção entre as fantasiassímbolos dos principais times de futebol do Rio Grande do Sul, Grêmio e Internacional, que como parte do enredo pontuavam com sua presença integrantes das duas torcidas agora transmutados em foliões. As reclamações giravam em torno dos materiais utilizados, que revelavam melhor produção para a fantasia do Grêmio e a falta de identificação da fantasia do Internacional, cujo símbolo era o saci-pererê.

Como apontamos, a fantasia é uma das ferramentas de comunicação do enredo, é a produção artística e arte do imaginário além do elemento agregador do integrante em um setor no desfile. Portar uma fantasia é um dos mecanismos da expressão de identidade(s) e, portanto, aparece com frequência nos estados de imaginação, de devaneio e de sociabilidade. Sem essas materializações, alguns componentes da ala do Internacional se sentiram frustrados por usar uma fantasia notadamente de qualidade inferior, sem brilhos e luxo, fato que ficou evidente quando estes se depararam com a fantasia que representava o time rival, essa de melhor qualidade e mais vistosa; o clima de insatisfação criado provocou a sensação de que o tão acalentado "sonho de desfilar no Rio" na realidade ia-se desfazendo à medida que a realidade se ia apresentando.

A transformação da fantasia do Internacional em "problema", distanciando-se de seu papel de sociabilização e integração, fica evidente quando não preenche os requisitos desse elemento comunicativo e artístico do desfile; a ilusão do luxo e do extraordinário cedendo lugar à ilusão do engano, do acirramento das rivalidades futebolísticas cotidianas, proporcionando falha na composição dos interesses do participante e da escola, bem como imprecisão de objeto e contexto.

Portar uma fantasia é buscar formas de integração e de diversão o que, nesse caso, não teria sido alcançado. A solução apresentada por integrantes da ala do Internacional, para permitir uma possível identificação do clube, foi escrever com batom vermelho o nome do 
time de futebol na testa ou nas bochechas, gerando um desvio da padronização estipulada pela produção e imprimindo algo de particular, de pessoal do próprio participante.

As rivalidades dos times de futebol existentes em momentos cotidianos se acentuaram pela diferença de produção entre as fantasias. Portar a fantasia do Grêmio, mais bonita, foi um motivo a mais, segundo Carla (gaúcha, componente da ala desse time) para "gozar com os colorados". ${ }^{4}$ Nesse caso, o apaziguamento de diferenças sociais, umas das características básicas do carnaval, não foi registrado, ocorrendo justamente o contrário, como é proposto pelas análises de Roberto DaMatta $(1977,1979)$.

Poder-se-ia pensar que as fantasias de mosqueteiro e de saci-pererê ${ }^{5}$ atraíssem gremistas e colorados, respectivamente. Observou-se, porém, que alguns torcedores de um time usavam a fantasia do outro. Nesses casos, apesar da paixão futebolística, a fantasia preencheu o pretexto da participação, indiferente ao tema a ser apresentado. Os motivos obedeciam a três aspectos que se inter-relacionavam: a opção por estar junto a seu grupo, que estaria com a fantasia do time rival; o custo; e o desejo de participação na avenida, independente da fantasia, que era maior do que seu pertencimento futebolístico.

Os desfiles representam, através da encenação e da in-

4 "Colorados" é como são chamados os torcedores do Internacional em razão de suas cores: vermeIho e branco.

5 Mosqueteiro e saci-pererê são os símbolos do Grêmio e do Internacional, respectivamente. É interessante assinalar que o saci-pererê é figura do imaginário afro-brasileiro e que se apresenta em um estado que se diz de "brancos" (OLIVEN, 1992).

tegração pessoal, uma ideia do real, englobando sentimentos de pertencer a um grupo - escola de samba - e estar em comunhão com todos. É interessante observar que alguns dos componentes da escola como sempre acontece, desejavam participar sem fantasia, só portando uma camisa de diretoria ou de apoio, o que não foi autorizado pela direção, pois é na fantasia que se dá o brilho visual da escola de samba na avenida. Já os gaúchos, cuja participação foi ocasional, captados na maioria por uma agência de turismo do Rio Grande do Sul, procuravam participar de qualquer maneira, ainda que usando fantasia de baixo custo e sem brilho, e que, embora representando um tipo de pertencimento muito particular, muito forte, não necessariamente indicava seu real envolvimento de torcedor (GOMBERG, 1998).

Nesse momento a participação, longe de ser fato isolado na sociedade complexa, constitui um processo de negociação de papéis sociais, de identidades e de visibilidades, dimensionando a primazia do carnaval sobre a paixão futebolística. Sobre a negociação de papéis sociais, Gilberto Velho (1994, p. 29) aponta que "o repertório de papéis sociais não só não está situado em um único plano, mas a sua própria existência está condicionada a essas múltiplas realidades".

Somada a sua função de comunicar, a fantasia possibilita ao desfilante "brincar carnaval" e vivenciar outras realidades. Dessa forma, ela age através de sua dimensão simbólica na ruptura com o cotidiano propiciada pelo carnaval e revela o imaginário através da transformação em múltiplas identidades.

GOMBERG, Estélio. Paixões e rivalidades futebolísticas em um desfile de escola de samba... 241 


\section{FECHAMENTO}

O sucesso da escola na avenida está relacionado à participação de todos os seus integrantes. A solidariedade torna-se assim imperativa entre os participantes sendo constantemente estimulada para que haja a manutenção do conjunto. Cada qual desempenha da melhor maneira sua atribuição em harmonia com os outros, e assim é construída a apresentação, que é coletiva. Nesse sentido, o desfile de escola de samba é a vivência e a comunicação em grupo - a mensagem ritualizada é emitida pela totalidade e em nome da agremiação.

Para alguns, desfilar não é somente brincar; afinal, a escola de samba está em julgamento. Portanto, está presente também a dimensão da responsabilidade na apresentação como maneira de obtenção de boas notas, já que o desfile é regido por quesitos. Para os gaúchos, a responsabilidade da participação somou-se à concretização de um sonho ao mesmo tempo em que possibilitou a celebração do Rio Grande do Sul como enredo de escola de samba no Rio de Janeiro. Samba, fantasias e alegorias colocam em cena as imagens do gaúcho, construindo uma narrativa em que ele é celebrado.

Na performance do conjunto, as conexões de dança, música, vestimentas, objetos e atitudes contribuem para o sucesso da apresentação. É importante mencionar que o público, tal como uma torcida, desempenha papel fundamental, sendo sua participação esperada no sentido de auxiliar, incentivar e apreciar a apresentação. O enredo utilizou diversos elementos que são considerados os mais expressivos quando se trata de Rio de Grande do Sul e gaúchos. Nele não houve compromisso com a história ou com a realidade a não ser aquele advindo da necessidade e da procura de trazer à imaginação determinado tema.

Pode-se mesmo dizer que as escolas de samba, ao longo de sua trajetória, primam pelo caráter de espetáculo e reproduzem a linguagem da ordem e da estrutura social vigente sem a atenção de crítica social, exaltando uma "nobre" história, o que é evidenciado pela maioria dos enredos desenvolvidos. Apesar disso, entretanto, é inegável que os enredos e os desfiles proporcionam diversão, trabalho, competição e vitalidade às escolas de samba.

Os diversos elementos constitutivos do que é conhecido como a "identidade gaúcha, especialmente a "paixão futebolística", foram adaptados e transformados num processo de construção de um espetáculo e, nesse sentido, podemos dizer que foram carnavalizados com vistas ao desfile.

Ponto alto de uma escola de samba, para o desfile voltam-se todas as suas atenções, mobilizam-se todos os seus integrantes e movimentam-se todos os seus recursos, mesmo aqueles que sugerem novas configurações para ordem social, sentimentos e identidades sociais. No momento do desfile, a escola de samba evidencia tensão estruturante entre "samba no pé" e "primazia do visual" - a Unidos de Vila Isabel optou por construir sua imagem associada ao primeiro aspecto identificando-se como "escola de raiz", escola de samba de bairro, de comunidade. No processo de afirmação vai-se ancorar na principal característica "da Vila", ou seja, o samba. 
Como participante do grupo especial, porém, necessita equilibrar essa opção, pois a "primazia do visual" é significativa no desfile, posto que regido por avaliações. Sua performance na avenida não pode, assim, depender apenas da competência de seus integrantes, mas precisa também apresentar um espetáculo visualmente exuberante. Assim não só é possível conquistar a primeira colocação como, aliás, garante sua permanência no grupo especial, aquele das mais famosas e renomadas - "as grandes escolas".

De um lado, estavam os integrantes da própria escola, aqueles que com ela mantêm relação íntima e permanente - são seus componentes de "raiz". De outro lado, em 1996 havia participantes que vieram do Rio Grande do Sul especialmente para esse desfile. A particularidade para esses participantes foi o enredo escolhido celebrar seu estado, agindo assim sobre outro sentimento de pertencimento, relacionado às suas origens.

Ainda que sua participação fosse de caráter ocasional, o desfile fez com que os sentimentos de pertencimento ao estado e, particularmente, ao time de futebol, fossem associados ao pertencimento à escola que, naquele momento, representava o Rio Grande do Sul. Assim, no desfile, todos esses pertencimentos convergiram para o objetivo central do acontecimento, ou seja, brincar o carnaval e ter sucesso na avenida. Naquele momento, os gaúchos tornaram-se "da Vila" e, simultaneamente, os "da Vila" transformaram-se em gaúchos.

Um entendimento possível para essa "pertença futebolística" pode decorrer da ideia de que o gaúcho celebrado pela escola não era de fato o gaúcho, e sim uma caricatura dele. No entanto, cabe também argumentar que o carnaval enquanto momento especial transforma a ordem estabelecida, criando metáforas e alegorias. Isso ocorre em virtude da situação especial proporcionada pelo carnaval, que atua jogando com a fantasia, a imaginação e o imaginário, situação própria de uma condição carnavalizada.

Em outra situação, poder-se-ia dizer que a troca de times de futebol, expressada no enredo através da fantasia, implica adulteração da "paixão futebolística". No entanto, numa situação de carnavalização, os elementos são transformados e ressemantizados em função das necessidades derivadas de construir um espetáculo procurando atuar com a imaginação e remetendo à fantasia.

Nesse sentido, gremista celebrou colorado, e colorado celebrou gremista, trazendo à cena a inversão e a exuberância tão próprias do carnaval do Rio de Janeiro.

Em 1996, gaúcho deu samba com gremistas de colorados e colorados de gremistas.

\section{REFERÊNCIAS BIBLIOGRÁFICAS}

BACZKO, Bronislaw. Imaginação social. In Enciclopédia Einaudi n. 5. Antropos-Homem. Lisboa: Imprensa Nacional Casa da Moeda, 1985.

BAKHTIN, Mikhail. The dialogic imagination. Austin: University of Texas Press, 1981. . A cultura popular na Idade Média e no Renascimento: o contexto de François Rabelais. São Paulo: Hucitec, 1987.

BAROJA, Julio Caro. El carnaval. Madrid: Taurus Ediciones, 1989. 
CAVALCANTI, Maria Laura Viveiros de Castro. Carnaval carioca: dos bastidores ao desfile. Rio de Janeiro: Funarte/Editora UFRJ, 1994.

DAMATTA, Roberto. O carnaval como um rito de passagens. Ensaios de antropologia estrutural. Petrópolis: Vozes, 2. ed., 1977. . Carnavais, malandros e heróis: para uma sociologia do dilema brasileiro. Rio de Janeiro: Zahar Editores, 1979. . (org.). Universo do futebol. Rio de Janeiro: Ed. Pinakoteke, 1985.

. Antropologia do óbvio: notas em torno do significado do futebol brasileiro. Revista USP, Dossiê Futebol, n. 22, 1994.

GOLDWASSER, Maria Júlia. O palácio do samba: estudo antropológico da escola de samba Estação Primeira de Mangueira. Rio de Janeiro: Zahar, 1975.

GOMBERG, Estélio. O enredo tchê no carnaval carioca: o gaúcho no desfile da escola de samba Unidos de Vila Isabel em 1996. Dissertação de Mestrado Porto Alegre: PPG Antropologia Social, UFRGS, 1998.

OLIVEN, Ruben George. A parte e o todo: a diversidade cultural no Brasil-nação. Petrópolis: Vozes, 1992.

MACIEL, Maria Eunice de Souza. Considerações sobre gaúchos e colonos. In BAQUERO, Marcello et alli. Diversidade étnica e identidade gaúcha. Santa Cruz do Sul: Editora da Unisc, 1994.

PESAVENTO, S. J. Os Farrapos. Nossa História, v. 2, n. 15, Rio de Janeiro, 2005, p. 54-58. . História do Rio Grande do Sul. Porto Alegre: Mercado Aberto, 1982.

QUEIROZ, Maria Isaura Pereira de. Carnaval brasileiro: o vivido e o mito. São Paulo: Brasiliense, 1992.

TURNER, Victor. O processo ritual: estrutura e antiestrutura. Petrópolis: Vozes, 1974.

VELHO, Gilberto. Projeto e metamorfose: antropologia das sociedades complexas. Rio de Janeiro: Jorge Zahar, 1994.

Estélio Gomberg é pós-doutorando em ciências sociais, doutor em saúde pública pela Universidade Federal da Bahia, bolsista Fapesb Pródoc I, coordenador estadual do Programa de Pesquisa para o Sistema Único de Saúde, em Sergipe (2003-2005), co-organizador (com Ana Cristina de Souza Mandarino) das coletâneas Racismos: olhares plurais, Leituras afro-brasileiras: territórios, religiosidades e saúdes e Leituras de novas tecnologias e saúde (Editora UFBA).

Artigo recebido em julho de 2010 e aceito para publicação em agosto 2010. 